\title{
Radiotherapy for glioblastoma patients with poor performance status
}

\author{
Christina Schröder ${ }^{1}$. Dorothee Gramatzki ${ }^{2}$ Erwin Vu ${ }^{1}$. Matthias Guckenberger ${ }^{1}$ Nicolaus Andratschke ${ }^{1}$. \\ Michael Weller ${ }^{2} \cdot$ Caroline Hertler ${ }^{1,2}$ (i)
}

Received: 12 May 2021 / Accepted: 18 August 2021 / Published online: 26 August 2021

(c) The Author(s) 2021

\begin{abstract}
Purpose There is limited information on treatment recommendations for glioblastoma patients with poor performance status. Here, we aim to evaluate the association of radiotherapy on survival in glioblastoma patients presenting with poor postoperative performance status in first-line setting.

Methods We retrospectively analyzed data of 93 glioblastoma patients presenting with poor postoperative performance status (ECOG 2-4) at the University Hospital Zurich, Switzerland, in the years 2005-2019. A total of 43 patients received radiotherapy with or without systemic therapy in the first-line setting, whereas 50 patients received no additive local or systemic treatment after initial biopsy or resection. Overall survival was calculated from primary diagnosis and from the end of radiotherapy. In addition, factors influencing survival were analyzed.

Results Median overall survival from primary diagnosis was 6.2 months in the radiotherapy group (95\% CI 6.2-14.8 weeks, range 2-149 weeks) and 2.3 months in the group without additive treatment (95\% CI 1.3-7.4 weeks, range 0-28 weeks) $(p<0.001)$. This survival benefit was confirmed by landmark analyses. Factors associated with overall survival were extent of resection and administration of radiotherapy with or without systemic treatment. Median survival from end of radiotherapy was 3 months (95\% CI 4.3-21.7 weeks, range $0-72$ weeks), with $25.6 \%(n=11)$ early termination of treatment and $83.7 \%$ $(n=36)$ requiring radiotherapy as in-patients. Performance status improved in $27.9 \%(n=12)$ of patients after radiotherapy. Conclusion In this retrospective single-institution analysis, radiotherapy improved overall survival in patients with poor performance status, especially in patients who were amendable to neurosurgical resection.
\end{abstract}

Keywords Glioblastoma $\cdot$ Radiation $\cdot$ Performance status $\cdot$ Survival

\section{Introduction}

Eighteen to $37 \%$ of glioblastoma patients present in a poor pre- or postoperative performance status at the time of diagnosis (Chang et al. 2003; Lutterbach et al. 2003; Bauchet et al. 2010; Gulati et al. 2011; Scott et al. 2012; Stark et al. 2012; Badaoui et al. 2014; McNamara et al. 2014; Zouaoui et al. 2014; Gramatzki et al. 2017). Performance status, age, mental status and extent of surgical resection have been confirmed as important prognostic factors in these patients, and

Caroline Hertler

caroline.hertler@usz.ch

1 Department of Radiation Oncology and Competence Center for Palliative Care, University Hospital Zurich, University of Zurich, Rämistrasse 100, 8091 Zurich, Switzerland

2 Department of Neurology, University Hospital Zurich, University of Zurich, Zurich, Switzerland low performance status at diagnosis indicates a particularly poor prognosis (Curran et al. 1993; Li et al. 2011; Scott et al. 2012).

The standard treatment of glioblastoma consists of surgery followed by radiotherapy in 30 fractions and concurrent and maintenance systemic therapy with temozolomide (TMZ) (Stupp et al. 2005; Wen et al. 2020; Weller et al. 2021). However, patients in poor performance status or elderly patients ( $>70$ years), are usually treated with adapted treatment regimens such as short course radiotherapy with or without chemotherapy, or alkylating chemotherapy only in $\mathrm{O}^{6}$-methylguanine-DNA methyltransferase (MGMT) promotor methylated patients (Roa et al. 2004; Malmstrom et al. 2012; Wick et al. 2012; Perry et al. 2017). Likewise, almost all clinical trials with experimental drugs preclude the enrolment of patients with poor performance status.

For elderly patients in good performance status, a survival benefit from radiotherapy after surgical resection of 
different extent has been confirmed (Keime-Guibert et al. 2007). However, data regarding the treatment of patients in poor performance status is scarce, especially considering that those patients are usually excluded from clinical trials, which minimizes the availability of data on potential benefit or harm for this selected patient group. A trial of 70 patients with a median Karnofsky performance status (KPS) of $60 \%$ compared the benefit of temozolomide therapy only to a historical control of patients treated with best supportive care. Temozolomide alone was characterized by acceptable tolerability especially in patients with a methylated MGMTpromotor and was associated with an improvement of the functional status. However, radiotherapy was not part of this study (Gallego Perez-Larraya et al. 2011).

To further evaluate a potential benefit of radiotherapy in patients with low performance status at diagnosis, we retrospectively analyzed the data of 43 patients with poor performance status receiving additive radiotherapy, either alone or in combination with chemotherapy, and of a control group of 50 patients receiving a diagnostic biopsy, partial or gross total resection without further tumor-targeted therapy.

\section{Material and methods}

\section{Data source}

We conducted a retrospective single center cohort study of glioblastoma patients $>18$ years at diagnosis, treated at the University Hospital Zurich between April 2005 and June 2019, with poor postoperative performance status (ECOG PS 2-4) after biopsy or neurosurgical resection in the firstline setting. Electronic patient files and pathology reports were the main source of data acquisition. The study was conducted in accordance with the Declaration of Helsinki and applicable regulatory requirements and has been approved by the local ethics committee (KEK-ZH-Nr. 2009-0135/1; KEK-ZH-Nr. 2015-0437).

\section{Disease and treatment characteristics}

All tumors were classified according to the World Health Organization (WHO) 2007 criteria in the local pathology department, for patients diagnosed before 2016, and according to the WHO 2016 criteria for patients diagnosed after that time. In a second step all tumors classified by the 2007 criteria were re-classified by IDH mutation status in accordance with the WHO 2016 classification when sufficient tissue was available. IDH1/2 status was obtained by immunohistochemistry or sequencing analysis; $M G M T$ promotor methylation status was determined by methylation-specific PCR. Extent of resection was assessed based on early postoperative imaging reports in all patients. For treatment planning, planning
CT scans as well as MRI were used. The gross tumor volume (GTV) was contoured as the primary tumor (if biopsy only) or the resection cavity including contrast-enhanced regions. A safety margin of $1.5 \mathrm{~cm}$ was added to derive the clinical target volume (CTV). An additional planning target volume (PTV) margin was added to compensate for setup errors. For grading of toxicity, CTCAE V. 5.0 was used.

\section{Statistical analysis}

Overall survival was calculated according to the Kaplan-Meier method. Overall survival from the time of surgery (biopsy or resection) to death or from end of radiotherapy to death were calculated. Additional factors were analyzed using the log-rank test. Univariate and multivariate analyses were done using Cox regression. The multivariate model was applied to all patients who had complete information on all tested co-variables. For statistical analysis of patient characteristics and performance status, the Chisquared test and the Fisher's exact test were used. For statistical analysis, SPSS Version 25 was used (SPSS IBM Corp., Armonk, NY, USA).

\section{Results}

\section{Patient characteristics}

We evaluated the data of 93 patients with glioblastoma and poor postoperative performance status (ECOG 2-4) that were treated at our institution between April 2005 and June 2019. Median age of patients was 69 years in the radiotherapy group and 73 in the control group $(p=0.236)$. Median postoperative ECOG was 2 for both the radiotherapy group and the control group. A total of 43 patients received additive radiotherapy, 18 of which after partial or gross total resection (GTR) and the remaining after tumor biopsy only. Most patients in the radiotherapy group were treated with $15 \times 2.67$ Gy $(n=35 ; 81.4 \%), 9.3 \%(n=4)$ were treated with $10 \times 3$ Gy and $9.3 \%(n=4)$ were treated with other fractionations. Additional concurrent or sequential systemic therapy was given in 19 patients, most frequently temozolomide during and/or after radiotherapy $(n=14 ; 32.6 \%)$. The patients in the control group received no tumor-specific treatment after surgical resection or biopsy (best supportive care). Further patient and treatment characteristics are summarized in Table 1 and in the supplementary file.

\section{Adherence and practical aspects of radiation treatment}

Compliance to radiotherapy was high with 32 patients $(74.4 \%)$ receiving the planned dose of radiotherapy. In 11 patients (25.6\%) treatment was terminated early because of a 
Table 1 Patient characteristics

\begin{tabular}{|c|c|c|c|c|c|c|}
\hline & \multicolumn{2}{|c|}{ Radiotherapy group } & \multicolumn{2}{|c|}{ Control group } & \multirow[t]{2}{*}{$p$ value } & \multirow{2}{*}{$\begin{array}{l}\text { Total } \\
N\end{array}$} \\
\hline & $N$ & $\%$ & $N$ & $\%$ & & \\
\hline \multicolumn{7}{|l|}{ Age (years) } \\
\hline Median & 69 & & 73 & & \multirow[t]{2}{*}{0.236} & \\
\hline Range & $56-85$ & & $29-90$ & & & \\
\hline \multicolumn{7}{|l|}{ Sex } \\
\hline Female & 19 & 44.2 & 22 & 44.0 & \multirow[t]{2}{*}{0.986} & 41 \\
\hline Male & 24 & 55.8 & 28 & 56.0 & & 52 \\
\hline \multicolumn{7}{|l|}{ ECOG } \\
\hline 2 & 29 & 31.2 & 28 & 30.1 & \multirow[t]{3}{*}{0.626} & 57 \\
\hline 3 & 13 & 14.0 & 20 & 21.5 & & 33 \\
\hline 4 & 1 & 1.1 & 2 & 2.2 & & 3 \\
\hline \multicolumn{7}{|l|}{ IDH } \\
\hline Wildtype & 38 & 88.4 & 45 & 90.0 & \multirow[t]{2}{*}{0.129} & 83 \\
\hline Mutated & 2 & 4.7 & 0 & 0.0 & & 2 \\
\hline Unknown & 3 & 7.0 & 5 & 10.0 & - & 8 \\
\hline \multicolumn{7}{|l|}{ MGMT status } \\
\hline Methylated & 7 & 16.3 & 9 & 18.0 & \multirow[t]{2}{*}{0.257} & 16 \\
\hline Unmethylated & 23 & 53.5 & 15 & 30.0 & & 38 \\
\hline Unknown & 13 & 30.2 & 26 & 52.0 & - & 39 \\
\hline \multicolumn{7}{|l|}{ Surgery $^{\mathrm{a}}$} \\
\hline Biopsy only & 25 & 58.1 & 26 & 52.0 & \multirow[t]{3}{*}{0.011} & 51 \\
\hline Partial resection & 7 & 16.3 & 20 & 40.0 & & 27 \\
\hline Gross total resection & 11 & 25.6 & 4 & 8.0 & & 15 \\
\hline \multicolumn{7}{|l|}{ Tumor localisation_1 } \\
\hline Deep structures & 9 & 20.9 & 13 & 26 & \multirow[t]{7}{*}{0.197} & 22 \\
\hline Frontal lobe & 12 & 27.9 & 12 & 24 & & 24 \\
\hline Temporal lobe & 11 & 25.6 & 7 & 14 & & 18 \\
\hline Parietal lobe & 8 & 18.6 & 5 & 10 & & 13 \\
\hline Occipital lobe & 3 & 7.0 & 10 & 20 & & 13 \\
\hline Infratentorial & 0 & 0 & 2 & 4 & & 2 \\
\hline Multifocal & 0 & 0 & 1 & 2 & & 1 \\
\hline \multicolumn{7}{|l|}{ Tumor localisation_2 } \\
\hline Bihemispheric & 3 & 7.0 & 10 & 20 & \multirow[t]{4}{*}{0.117} & 13 \\
\hline Left hemisphere & 17 & 39.5 & 13 & 26 & & 30 \\
\hline Right hemisphere & 23 & 53.5 & 25 & 50 & & 48 \\
\hline Infratentorial & 0 & 0 & 2 & 4 & & 2 \\
\hline \multicolumn{7}{|l|}{ Planned radiation therapy } \\
\hline $15 \times 2.67 \mathrm{~Gy}$ & 35 & 81.4 & $\mathrm{n} . \mathrm{a}$ & n.a & & 35 \\
\hline $10 \times 3 \mathrm{~Gy}$ & 4 & 9.3 & n.a & n.a & & 4 \\
\hline Other & 4 & 9.3 & n.a & n.a & & 4 \\
\hline \multicolumn{7}{|l|}{$\begin{array}{l}\text { Systemic treatment (part of first- } \\
\text { line treatment) }\end{array}$} \\
\hline None & 24 & 55.8 & n.a & n.a & & 24 \\
\hline TMZ before RT & 3 & 7.0 & n.a & n.a & & 3 \\
\hline TMZ during and/or after RT & 14 & 32.6 & n.a & n.a & & 14 \\
\hline CCNU after RT & 2 & 4.7 & n.a & n.a & & 2 \\
\hline Bevacizumab after RT & 7 & 16.3 & n.a & n.a & & 7 \\
\hline
\end{tabular}

${ }^{a}$ Sign difference RT group and control group $(p<0.05$, Chi-Squared test) 
decline in performance status, either as the result of disease progression or due to pre-existing morbidity. A total of 36 patients $(83.7 \%)$ received radiation treatment as in-patients for at least a part of the treatment. In 14 patients (32.6\%) a specialized palliative care team was involved at some point during radiotherapy treatment. Radiotherapy was well tolerated with no $\geq \mathrm{G} 3$ toxicities.

\section{Overall survival}

At the time of analysis, median follow-up of living patients was 2 weeks (95\% CI 0.0-6.8) and six patients were still alive. The median survival after primary diagnosis was 27 weeks (95\% CI 6.2-14.8, range 2-149) for patients treated with radiotherapy and 10 weeks $(95 \% \mathrm{CI}$ 1.3-7.4, range 0-28) for the patients in the control group (Fig. 1A) $(p<0.001)$. Patients that received a biopsy only had a median survival from diagnosis of 13 weeks $(95 \%$ CI 2.6-23.4, range 2-149) when treated with radiotherapy $(n=25)$ and 7 weeks (95\% CI 3.4-10.6, range 0-19) with best supportive care $(n=26)$ (Fig. 2A) $(p<0.001)$. Older patients $\geq 70$ years had a median overall survival of 28 weeks (95\% CI 14.1-41.9, range 3-66) when treated with radiotherapy, and 10 weeks in the best supportive care group (95\% CI 6.0-14.0, range 0-28) (Fig. 2C) $(p<0.001)$. When separated by ECOG, patients with poor ECOG (3-4) showed a median overall survival of 22 weeks (95\% CI 5.5-38.5, range 2-61) when treated with radiotherapy versus 7 weeks with best supportive care (95\% CI 4.4-9.6, range $0-25$ weeks) (Fig. 2E) $(p<0.001)$ (Table 2). In addition, a 4- and 8-week landmark analysis was performed to estimate OS without immortal time bias (Fig. 3A, B) showing similar results compared to analysis at diagnosis. Extent of surgical resection $(p=0.037)$ and postoperative treatment [either radiotherapy only $(p=0.002)$ or in combination with

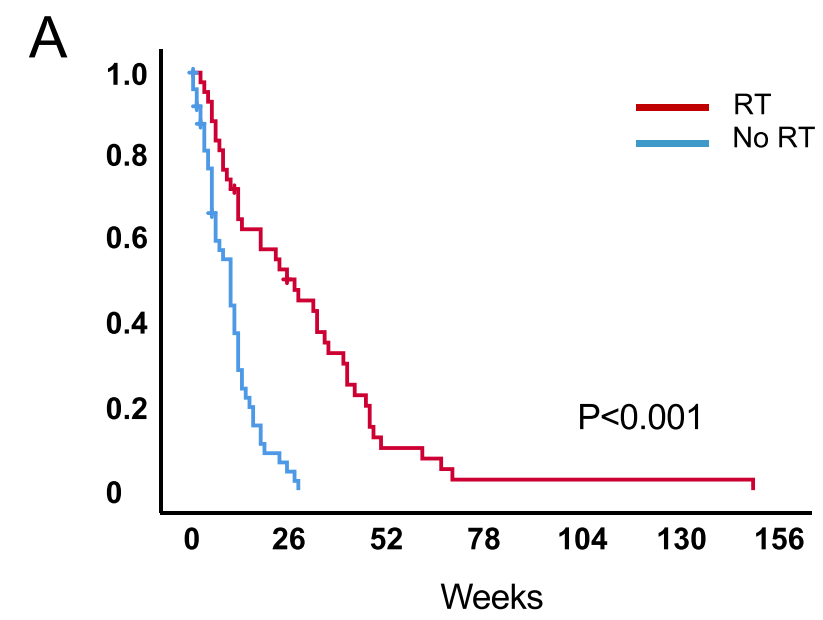

Fig. 1 Overall survival in patients with newly diagnosed glioblastoma and ECOG $\geq 2$ stratified by treatment vs. no treatment $\mathbf{a}$ systemic therapy $(p<0.001)]$ showed statistical significance in univariate analysis and remained significant in multivariate analysis (Tables 3, 4).

\section{Post-radiation survival}

The median survival after radiotherapy (post-radiation survival) was 13 weeks (3 months, 95\% CI 4.3-21.7 weeks, range 0-72 weeks). Twelve patients (27.9\%) treated with radiotherapy died within 4 weeks after radiotherapy, 10 of which had a biopsy only (83.3\%). Post-radiation survival did not differ significantly when stratified for extent of resection, age group or ECOG at diagnosis (Fig. 2B, D, F) (Table 2).

\section{Performance status}

After RT, the performance status was improved at any follow-up appointment during the first 3 months in 12 patients (27.9\%). The median increase in performance status was 1 with a range of $1-2$. Seven patients (16.3\%) of patients regained a performance status $\leq 1$. Factors associated with an improvement in performance status within the radiation therapy group were extent of resection (biopsy only vs. partial resection vs. gross total resection, $p=0.039$ ), combined use of systemic therapy $(p=0.001)$ and delivered radiotherapy dose ( $<40$ vs $\geq 40 \mathrm{~Gy}, p=0.007)$. It has to be noted that in $75 \%$ of patients with a radiotherapy dose $<40 \mathrm{~Gy}$, radiotherapy had to be terminated early. The majority of patients with an improvement in performance status had a gross total resection, received systemic therapy and all had received a radiation dose of $\geq 40$ Gy. Age, MGMT status and the initial performance status were not associated with improvement in performance status after radiotherapy.

\section{Discussion}

This retrospective single-institution analysis addressed the value of radiotherapy compared to best supportive care in glioblastoma patients with poor postoperative performance status in the first-line setting.

Performance status is a well-documented prognostic factor for overall survival in glioblastoma patients, the most important factors being age ( $<50$ vs. $\geq 50$ years) (Curran et al. 1993; Li et al. 2011) or type of surgery (Gross total resection/partial resection vs. biopsy) (Scott et al. 2012). However, with regard to the optimal treatment recommendation of patients in poor performance status, reliable data is sparse (Curran et al. 1993; Lutterbach et al. 2003; Li et al. 2011; Scott et al. 2012; Stark et al. 2012; McNamara et al. 2014; Gately et al. 2016; Glynn, Rangaswamy et al. 2019). The median overall survival of patients with poor performance status is short with 2.3-6.6 months from the time 
Overall survival
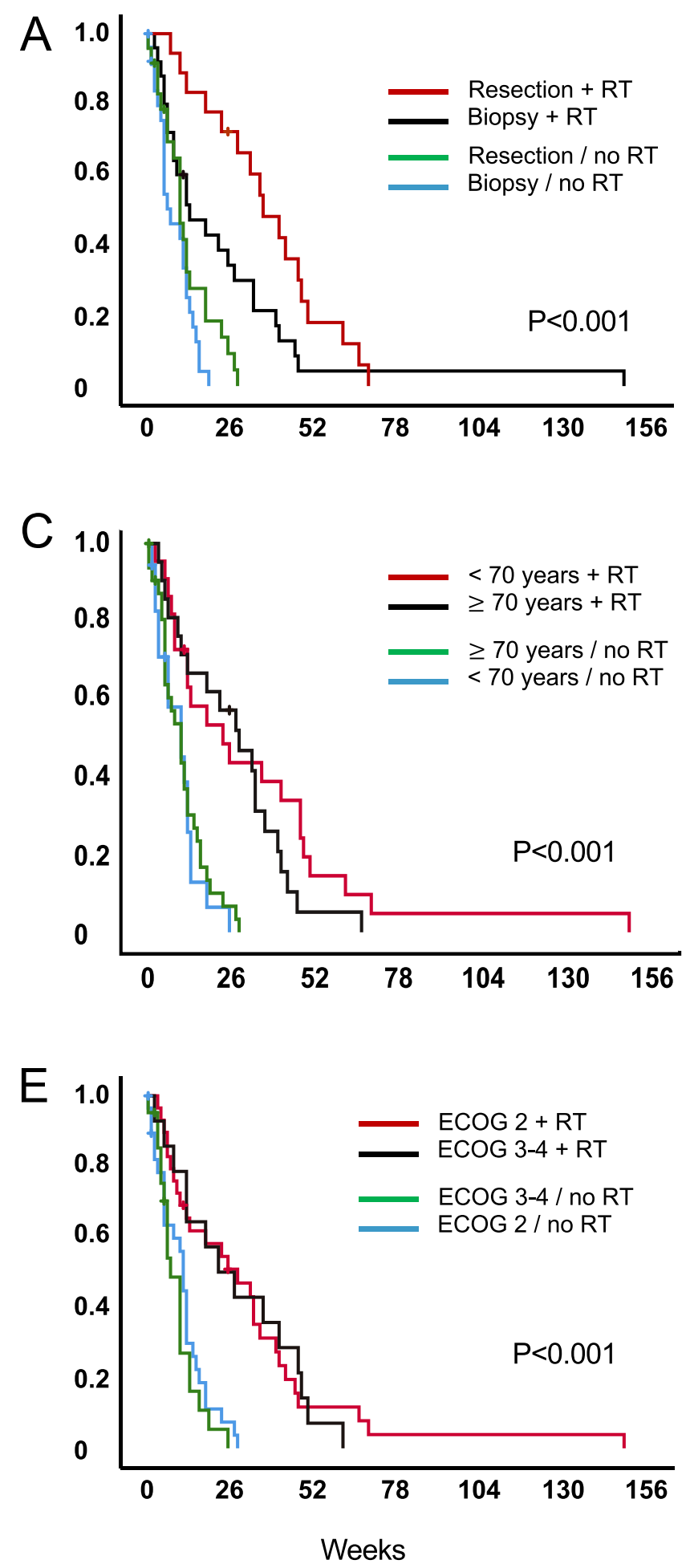

Post-radiation survival

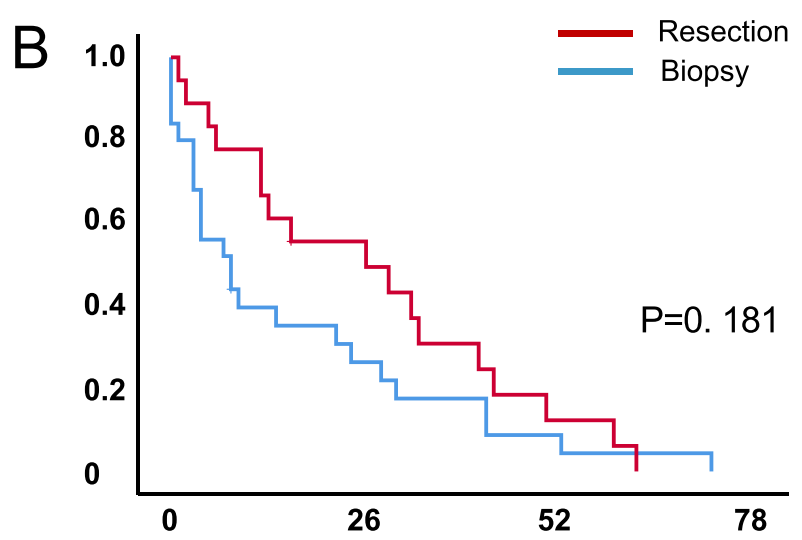

D
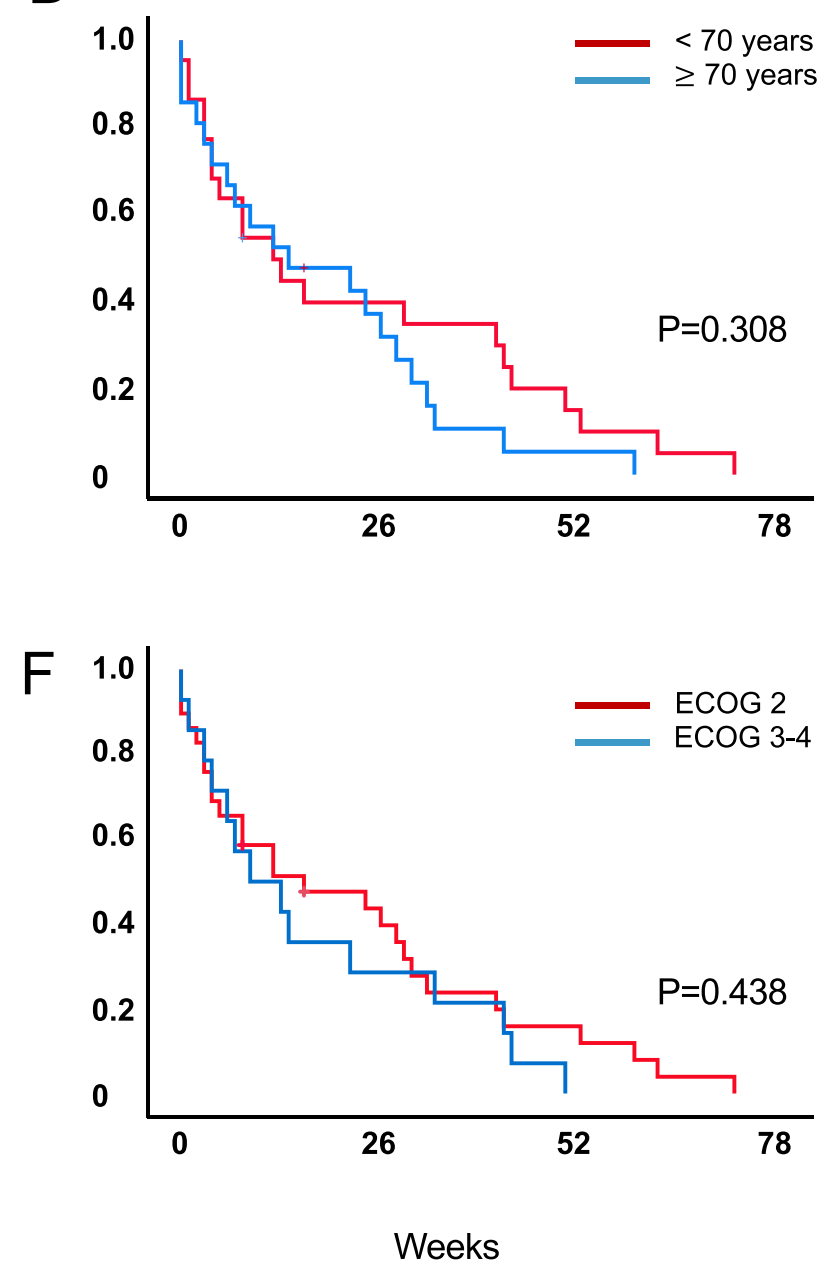

Fig. 2 Overall survival of the whole population (left) and survival from end of RT in the treatment group (right) were stratified by extent of resection (resection vs. biopsy) a, b; age group ( $<70$ years vs $\geq 70$ years) $\mathbf{c}, \mathbf{d}$; and ECOG at diagnosis (2 vs. $2-3$ ) e, f 
Table 2 Survival data (log rank analysis)

\begin{tabular}{|c|c|c|c|c|c|c|c|c|}
\hline \multirow[b]{2}{*}{ Survival } & \multicolumn{4}{|c|}{ From diagnosis } & \multicolumn{4}{|c|}{ From RT } \\
\hline & $N$ & $\begin{array}{l}\text { Median OS } \\
\text { (weeks) }\end{array}$ & $95 \% \mathrm{CI}$ & $p$ value & $N$ & $\begin{array}{l}\text { Median OS } \\
\text { (weeks) }\end{array}$ & $95 \% \mathrm{CI}$ & $p$ value \\
\hline All patients & 93 & 12 & $9.9-14.1$ & & 43 & 13 & $4.3-21.7$ & \\
\hline \multicolumn{9}{|l|}{ RT } \\
\hline Yes & 43 & 27 & $6.2-14.8$ & $<0.001$ & & n.a & n.a & n.a \\
\hline No & 50 & 10 & $1.3-7.4$ & & & & & \\
\hline \multicolumn{9}{|l|}{ Age } \\
\hline$<70$ with RT & 22 & 23 & $5.4-40.6$ & $<0.001$ & 22 & 12 & $3.1-20.9$ & 0.308 \\
\hline$<70$ no RT & 18 & 10 & $3.7-16.3$ & & & & & \\
\hline$\leq 70$ with RT & 21 & 28 & $14.1-41.9$ & & 21 & 14 & $0.0-32.7$ & \\
\hline$\geq 70$ no RT & 32 & 10 & $6.0-14.0$ & & & & & \\
\hline \multicolumn{9}{|l|}{ ECOG } \\
\hline $\begin{array}{l}2 \\
\text { with RT }\end{array}$ & 29 & 28 & $10.8-45.2$ & & 29 & 16 & $0-35.7$ & 0.438 \\
\hline $\begin{array}{c}2 \\
\text { no RT }\end{array}$ & 29 & 11 & $9.3-12.7$ & & & & & \\
\hline $\begin{array}{l}3-4 \\
\text { with RT }\end{array}$ & 14 & 22 & $5.5-8.5$ & & 14 & 9 & $0-26.7$ & \\
\hline $\begin{array}{c}3-4 \\
\text { no RT }\end{array}$ & 21 & 7 & $4.4-9.6$ & & & & & \\
\hline \multicolumn{9}{|l|}{ Surgery } \\
\hline Biopsy with RT & 25 & 13 & $2.6-23.4$ & $<0.001$ & 25 & 8 & $1.5-14.5$ & 0.181 \\
\hline Biopsy no RT & 26 & 7 & $3.4-10.6$ & & & & & \\
\hline PR/GTR with RT & 18 & 36 & $24.2-47.8$ & & 18 & 26 & $1.4-50.6$ & \\
\hline PR/GTR no RT & 24 & 10 & $7.3-12.7$ & & & & & \\
\hline
\end{tabular}

\section{Landmark analysis at 4 weeks}

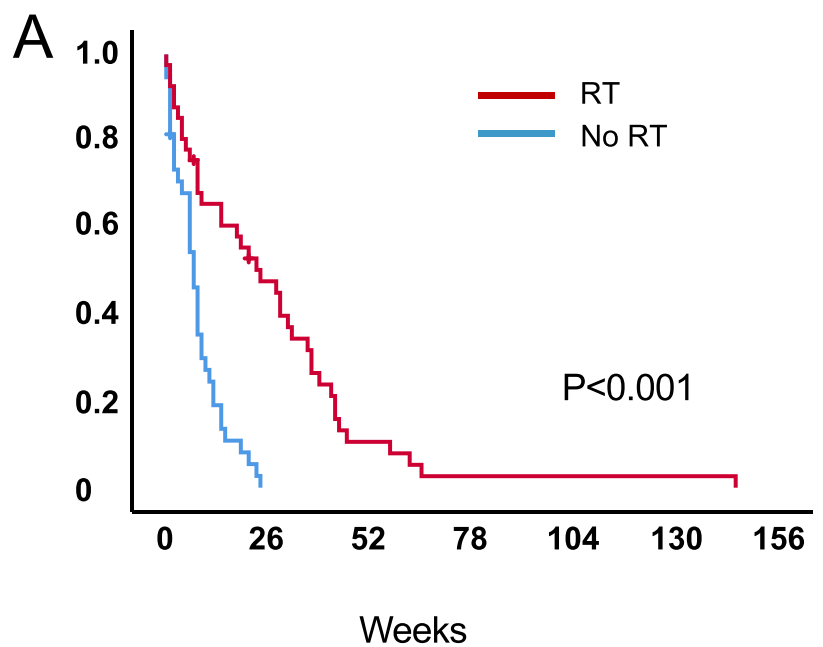

\section{Landmark analysis at 8 weeks}

B

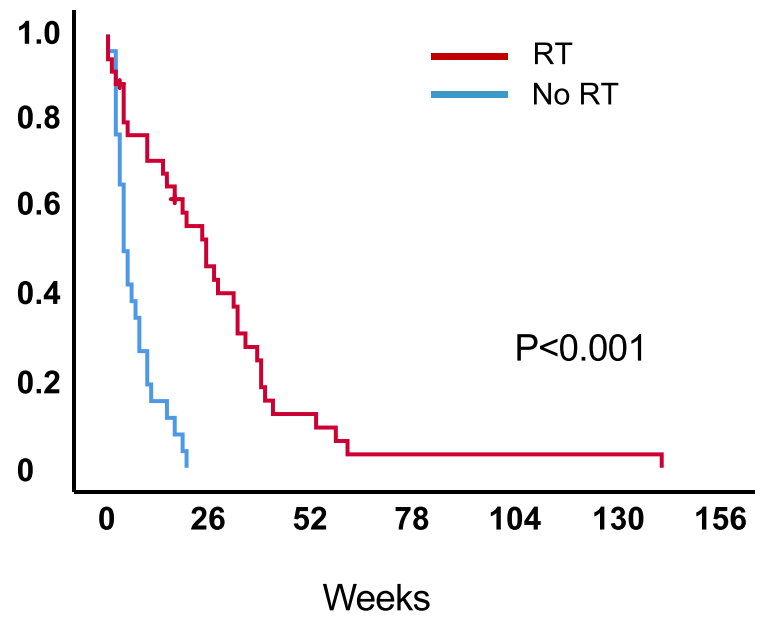

Fig. 3 Overall survival of the whole population stratified by treatment vs. no treatment. Landmark analyses were performed at 4 weeks a and 8 weeks b

of diagnosis, although the definition of poor performance status is inconsistent. In a cohort published by Scott et al., patients with biopsy only and a KPS $<70 \%$ had a median OS of 2.3 months. Patients with more extensive surgeries had a better overall survival, independent of performance status (Scott et al. 2012). Marina et al. analyzed data of patients with a KPS $<50 \%$ in a cohort with about half of patients biopsied only, and $64 \%$ of patients receiving radiotherapy, 
Table 3 Univariate analysis with regards to death (Cox regression analysis)
Table 4 Multivariate analysis with regards to death (Cox regression analysis)

\begin{tabular}{|c|c|c|c|}
\hline & $\begin{array}{l}N \\
\text { (events) }\end{array}$ & HR $(95 \%$ CI $)$ & $p$ value \\
\hline \multicolumn{4}{|l|}{ Age } \\
\hline$<70$ years & $40(37)$ & $0.74(0.48-1.16)$ & 0.190 \\
\hline$\geq 70$ years & $53(50)$ & ref & \\
\hline \multicolumn{4}{|l|}{ Gender } \\
\hline Male & $52(48)$ & ref & \\
\hline Female & $41(39)$ & $1.13(0.74-1.74)$ & 0.565 \\
\hline \multicolumn{4}{|l|}{ ECOG } \\
\hline 2 & $58(54)$ & $0.87(0.56-1.35)$ & 0.527 \\
\hline $3 / 4$ & $35(33)$ & ref & \\
\hline \multicolumn{4}{|l|}{ Extent of resection } \\
\hline Biopsy & $51(48)$ & $1.58(1.03-2.43)$ & 0.037 \\
\hline $\begin{array}{l}\text { Resection } \\
\text { (partial/gross total resection) }\end{array}$ & $42(39)$ & ref & \\
\hline \multicolumn{4}{|l|}{ MGMT promoter methylation status } \\
\hline Unmethylated & $38(37)$ & ref & \\
\hline Methylated & $16(13)$ & $0.91(0.49-1.70)$ & 0.766 \\
\hline \multicolumn{4}{|l|}{ Treatment } \\
\hline No tumor-specific treatment & $50(46)$ & ref & \\
\hline Radiotherapy & $24(24)$ & $0.42(0.24-0.74)$ & 0.002 \\
\hline Radiotherapy plus systemic treatment & $19(17)$ & $0.13(0.06-0.26)$ & $<0.001$ \\
\hline
\end{tabular}

\begin{tabular}{|c|c|c|c|}
\hline & $N$ (events) & $\operatorname{HR}(95 \% \mathrm{CI})$ & $p$ value \\
\hline All patients & $54(51)$ & & \\
\hline \multicolumn{4}{|l|}{ Age } \\
\hline$<70$ years & 26 & $1.40(0.69-2.81)$ & 0.352 \\
\hline$\geq 70$ years & 28 & Ref & \\
\hline \multicolumn{4}{|l|}{ Gender } \\
\hline Male & 25 & Ref & \\
\hline Female & 29 & $2.87(1.46-5.67)$ & 0.002 \\
\hline \multicolumn{4}{|l|}{ ECOG } \\
\hline 2 & 33 & $0.94(0.52-1.70)$ & 0.839 \\
\hline $3 / 4$ & 21 & Ref & \\
\hline \multicolumn{4}{|l|}{ Extent of resection } \\
\hline Biopsy & 25 & $3.93(1.94-7.93)$ & $<0.001$ \\
\hline $\begin{array}{l}\text { Resection } \\
\text { (partial/gross total resection) }\end{array}$ & 29 & Ref & \\
\hline \multicolumn{4}{|l|}{ MGMT promoter methylation status } \\
\hline Unmethylated & 38 & Ref & \\
\hline Methylated & 16 & $0.84(0.43-1.62)$ & 0.600 \\
\hline \multicolumn{4}{|l|}{ Treatment } \\
\hline No tumor-specific treatment & 24 & Ref & \\
\hline Radiotherapy & 14 & $0.26(0.12-0.59)$ & 0.001 \\
\hline Radiotherapy plus systemic treatment & 16 & $0.09(0.03-0.25)$ & $<0.001$ \\
\hline
\end{tabular}

and reported a median overall survival from the date of the most excessive surgery of 2.3 month, too (Marina et al. 2011).
In our cohort, the median survival from diagnosis was 27 weeks in all patients treated with radiotherapy, and 13 weeks in the biopsy only followed by radiotherapy group. 
Survival from the end of radiotherapy was median 13 weeks for all patients treated with radiotherapy and 8 weeks for biopsy followed by radiotherapy. This indicates patients treated with biopsy only are at increased risk of early death irrespective of post-biopsy radiotherapy. Admittedly, our radiotherapy group comprised more patients with gross total resection compared to the best supportive care group. Yet, without post-surgery radiotherapy, survival does not increase with gross total resection compared to biopsy only, underlining the role of radiotherapy (Fig. 2A, B), and the median overall survival from diagnosis was significantly better in the radiotherapy group than in the control group (10 weeks) irrespective of performance status or extent of surgical resection. Landmark analyses at 4 and 8 weeks confirmed the survival benefit in the radiotherapy group (Fig. 3).

In patients with poor performance status, survival is only one aspect to consider. Another important question is whether impaired patients may benefit from radiation therapy in terms of performance status improvement. Very few data are available on this topic, and especially prospective data is rare. Retrospective data and data from a phase II trial suggest that KPS might improve by $10-30 \%$ in up to $70 \%$ patients with radiotherapy, but overall patient numbers are small (Gallego Perez-Larraya et al. 2011; Marina et al. 2011; Reyngold et al. 2012). In this analysis, 30\% of patients had an improvement in performance status of 1-2 after radiotherapy, consistent with previous data. One fifth of our patient population regained an ECOG $\geq 1$, allowing for self-care, and therefore representing a factor of autonomy for the patient.

Another factor to consider is treatment-induced toxicity. Radiation-induced toxicity for glioblastoma patients is usually low, e.g., $8 \% \geq \mathrm{G} 3$ toxicity in the radiation arm (Malmstrom et al. 2012; Wick et al. 2012) in a group of elderly, therefore more vulnerable, patients. This is confirmed in our study with no case of grade 3 or higher radiation-induced toxicity. Treatment with TMZ, either as monotherapy or with radiation, causes mostly hematologic $\leq \mathrm{G} 3$ toxicity in up to $25 \%$ of patients (Stupp et al. 2005; Gallego Perez-Larraya et al. 2011; Malmstrom et al. 2012).

Short course radiation treatment is the standard of care in elderly and poor-performance status patients with unmethylated MGMT-promotor (Guedes de Castro et al. 2017; Weller et al. 2017), which limits the total treatment time to 3 weeks and 15 radiotherapy sessions. All patients in our study were treated with hypo-fractionated radiotherapy; however, it was interesting that the benefit of radiotherapy was restricted to patients treated with 40.05 Gy in 15 fractions, whereas no benefit was observed for lower-dose radiotherapy. Bestsupportive care or shorter fractionated radiotherapy should, therefore, be considered for patients not eligible for a fullcourse radiotherapy of 15 fractions over three weeks.
Despite absolute overall survival is short in glioblastoma patients with poor performance status, as reported above, radiotherapy was well-tolerated as delivered over maximum three weeks and appears favorable considering that median overall survival is prolonged by a factor of almost three. However, careful and balanced patient information about the absolute and relative benefits of surgery and postoperative radiotherapy and chemotherapy is mandatory.

Limitations of this study include the retrospective nature of this small population with heterogeneous treatment, including combination of chemotherapeutics with radiotherapy as part of the first-line treatment. However, there was no significant imbalance with regard to MGMT promotor methylation as predictive marker in the radiotherapy plus systemic treatment group, which could have indicated a better response to additional chemotherapy. Also, lack of patient-reported outcomes in this retrospective analysis precludes a statement on subjective benefits and quality of life in this specific patient population, therefore omitting a relevant patient-centered outcome surrogate. Still, the inclusion of relevant numbers of patients biopsied only, in both radiotherapy and control group ( 25 vs. 26 patients, respectively), provides more information on this patient group with poor predictors of outcome that may benefit with regard to the performance status improvement.

In conclusion, this retrospective single-institution analysis observed a significant and clinically relevant overall survival benefit of radiotherapy in glioblastoma patients with poor performance status. However, considering the short absolute overall survival, especially in patients not eligible for neurosurgical resection, the potential benefit of prolonged survival must be carefully weighted against the large portion of extended lifespan being spent under treatment. Better prognostic and predictive factors for patient selection are urgently needed. Most importantly, quality-oflife and patient-reported outcome need to be considered in addition to sole overall survival and should be incorporated not only into clinical studies, but also as routine practice, including patients in reduced performance status who are usually excluded from study populations (Coomans et al. 2019; Hertler et al. 2020).

Supplementary Information The online version contains supplementary material available at https://doi.org/10.1007/s00432-021-03770-9.

Author contributions CS, DG and CH designed the project setup, collected data, performed analyses and wrote the manuscript with input from all authors. EV collected data and performed analyses. MG, NA and MW reviewed the manuscript and contributed to the final version of the manuscript. All authors contributed to the final version of the manuscript. 
Funding Open Access funding provided by Universität Zürich. This work was supported by a personal grant from the "Filling the gap" program of the University of Zurich, Switzerland to $\mathrm{CH}$.

\section{Declarations}

Conflict of interest The authors declare no conflict of interest or financial interest related to this publication.

Ethical approval The study was approved by the Ethics Committee and, wherever applicable, patients consented to retrospective data collection including use of encoded data for publication. (KEK-ZH-Nr. 2009-0135/1; KEK-ZH-Nr. 2015-0437).

Data availability No data are available.

Open Access This article is licensed under a Creative Commons Attribution 4.0 International License, which permits use, sharing, adaptation, distribution and reproduction in any medium or format, as long as you give appropriate credit to the original author(s) and the source, provide a link to the Creative Commons licence, and indicate if changes were made. The images or other third party material in this article are included in the article's Creative Commons licence, unless indicated otherwise in a credit line to the material. If material is not included in the article's Creative Commons licence and your intended use is not permitted by statutory regulation or exceeds the permitted use, you will need to obtain permission directly from the copyright holder. To view a copy of this licence, visit http://creativecommons.org/licenses/by/4.0/.

\section{References}

Badaoui N, Meyronet D, Cartalat-Carel S, Guyotat J, Jouanneau E, d'Hombres A, Sunyach MP, Jouvet A, Louis-Tisserand G, Archinet A, Frappaz D, Bauchet L, Honnorat J, Ducray F (2014) Patterns of care and survival of glioblastoma patients: a comparative study between 2004 and 2008 in Lyon, France. Rev Neurol (paris) 170(3):222-227

Bauchet L, Mathieu-Daude H, Fabbro-Peray P, Rigau V, Fabbro M, Chinot O, Pallusseau L, Carnin C, Laine K, Schlama A, Thiebaut A, Patru MC, Bauchet F, Lionnet M, Wager M, Faillot T, Taillandier L, Figarella-Branger D, Capelle L, Loiseau H, Frappaz D, Campello C, Kerr C, Duffau H, Reme-Saumon M, Tretarre B, Daures JP, Henin D, Labrousse F, Menei P, Honnorat J, N Societe Francaise de, Club de Neuro-Oncologie of the Societe Francaise de N, Societe Francaise de and F Association des Neuro-Oncologues d'Expression (2010) Oncological patterns of care and outcome for 952 patients with newly diagnosed glioblastoma in 2004 . Neuro Oncol 12(7):725-735

Chang SM, Parney IF, McDermott M, Barker FG 2nd, Schmidt MH, Huang W, Laws ER Jr, Lillehei KO, Bernstein M, Brem H, Sloan AE, Berger M, Glioma Outcomes I (2003) Perioperative complications and neurological outcomes of first and second craniotomies among patients enrolled in the Glioma outcome project. J Neurosurg 98(6):1175-1181

Coomans M, Dirven L, Baumert van den Bent Bottomley Brandes Chinot Coens Gorlia Herrlinger Keime-Guibert Malmstrom Martinelli Stupp Talacchi Weller Wick Reijneveld Taphoorn KANBGMAAAOCTUFAFRAMWJCMJB, E. Q. o. L. Group and E. B. T. G. the (2019) The added value of health-related quality of life as a prognostic indicator of overall survival and progression-free survival in glioma patients: a meta-analysis based on individual patient data from randomised controlled trials. Eur J Cancer 116:190-198

Curran WJ Jr, Scott CB, Horton J, Nelson JS, Weinstein AS, Fischbach AJ, Chang CH, Rotman M, Asbell SO, Krisch RE et al (1993) Recursive partitioning analysis of prognostic factors in three Radiation Therapy Oncology Group malignant glioma trials. J Natl Cancer Inst 85(9):704-710

Gallego Perez-Larraya J, Ducray F, Chinot O, Catry-Thomas I, Taillandier L, Guillamo JS, Campello C, Monjour A, Cartalat-Carel S, Barrie M, Huchet A, Beauchesne P, Matta M, Mokhtari K, Tanguy ML, Honnorat J, Delattre JY (2011) Temozolomide in elderly patients with newly diagnosed glioblastoma and poor performance status: an ANOCEF phase II trial. J Clin Oncol 29(22):3050-3055

Gately L, Collins A, Murphy M, Dowling A (2016) Age alone is not a predictor for survival in glioblastoma. J Neurooncol 129(3):479-485

Glynn AM, Rangaswamy G, O’Shea J, Dunne M, Grogan R, MacNally S, Fitzpatrick D, Faul C (2019) Glioblastoma Multiforme in the over 70's: to treat or not to treat with radiotherapy? Cancer Med 8:4669-4677

Gramatzki D, Kickingereder P, Hentschel B, Felsberg J, Herrlinger U, Schackert G, Tonn JC, Westphal M, Sabel M, Schlegel U, Wick W, Pietsch T, Reifenberger G, Loeffler M, Bendszus M, Weller M (2017) Limited role for extended maintenance temozolomide for newly diagnosed glioblastoma. Neurology 88(15):1422-1430

Guedes de Castro D, Matiello J, Roa W, Ghosh S, Kepka L, Kumar N, Sinaika V, Lomidze D, Hentati D, Rosenblatt E, Fidarova E (2017) Survival outcomes with short-course radiation therapy in elderly patients with glioblastoma: data from a randomized phase 3 trial. Int J Radiat Oncol Biol Phys 98(4):931-938

Gulati S, Jakola AS, Nerland US, Weber C, Solheim O (2011) The risk of getting worse: surgically acquired deficits, perioperative complications, and functional outcomes after primary resection of glioblastoma. World Neurosurg 76(6):572-579

Hertler C, Seiler A, Gramatzki D, Schettle M, Blum D (2020) Sexspecific and gender-specific aspects in patient-reported outcomes. ESMO Open 5(Suppl 4):e000837

Keime-Guibert F, Chinot O, Taillandier L, Cartalat-Carel S, Frenay M, Kantor G, Guillamo JS, Jadaud E, Colin P, Bondiau PY, Menei P, Loiseau H, Bernier V, Honnorat J, Barrie M, Mokhtari K, Mazeron JJ, Bissery A, Delattre JY, N-O Association of FrenchSpeaking (2007) Radiotherapy for glioblastoma in the elderly. N Engl J Med 356(15):1527-1535

Li J, Wang M, Won M, Shaw EG, Coughlin C, Curran WJ Jr, Mehta MP (2011) Validation and simplification of the Radiation Therapy Oncology Group recursive partitioning analysis classification for glioblastoma. Int J Radiat Oncol Biol Phys 81(3):623-630

Lutterbach J, Sauerbrei W, Guttenberger R (2003) Multivariate analysis of prognostic factors in patients with glioblastoma. Strahlenther Onkol 179(1):8-15

Malmstrom A, Gronberg BH, Marosi C, Stupp R, Frappaz D, Schultz H, Abacioglu U, Tavelin B, Lhermitte B, Hegi ME, Rosell J, Henriksson R, G. Nordic Clinical Brain Tumour Study (2012) Temozolomide versus standard 6-week radiotherapy versus hypofractionated radiotherapy in patients older than 60 years with glioblastoma: the Nordic randomised, phase 3 trial. Lancet Oncol 13(9):916-926

Marina O, Suh JH, Reddy CA, Barnett GH, Vogelbaum MA, Peereboom DM, Stevens GH, Elinzano H, Chao ST (2011) Treatment outcomes for patients with glioblastoma multiforme and a low Karnofsky Performance Scale score on presentation to a tertiary care institution. Clinical article. J Neurosurg 115(2):220-229

McNamara MG, Lwin Z, Jiang H, Chung C, Millar BA, Sahgal A, Laperriere N, Mason WP (2014) Conditional probability of 
survival and post-progression survival in patients with glioblastoma in the temozolomide treatment era. J Neurooncol 117(1):153-160

Perry JR, Laperriere N, O'Callaghan CJ, Brandes AA, Menten J, Phillips C, Fay M, Nishikawa R, Cairncross JG, Roa W, Osoba D, Rossiter JP, Sahgal A, Hirte H, Laigle-Donadey F, Franceschi E, Chinot O, Golfinopoulos V, Fariselli L, Wick A, Feuvret L, Back M, Tills M, Winch C, Baumert BG, Wick W, Ding K, Mason WP, Trial I (2017) Short-course radiation plus temozolomide in elderly patients with glioblastoma. N Engl J Med 376(11):1027-1037

Reyngold M, Lassman AB, Chan TA, Yamada Y, Gutin PH, Beal K (2012) Abbreviated course of radiation therapy with concurrent temozolomide for high-grade glioma in patients of advanced age or poor functional status. J Neurooncol 110(3):369-374

Roa W, Brasher PM, Bauman G, Anthes M, Bruera E, Chan A, Fisher B, Fulton D, Gulavita S, Hao C, Husain S, Murtha A, Petruk K, Stewart D, Tai P, Urtasun R, Cairncross JG, Forsyth P (2004) Abbreviated course of radiation therapy in older patients with glioblastoma multiforme: a prospective randomized clinical trial. J Clin Oncol 22(9):1583-1588

Scott JG, Bauchet L, Fraum TJ, Nayak L, Cooper AR, Chao ST, Suh JH, Vogelbaum MA, Peereboom DM, Zouaoui S, Mathieu-Daude H, Fabbro-Peray P, Rigau V, Taillandier L, Abrey LE, DeAngelis LM, Shih JH, Iwamoto FM (2012) Recursive partitioning analysis of prognostic factors for glioblastoma patients aged 70 years or older. Cancer 118(22):5595-5600

Stark AM, van de Bergh J, Hedderich J, Mehdorn HM, Nabavi A (2012) Glioblastoma: clinical characteristics, prognostic factors and survival in 492 patients. Clin Neurol Neurosurg 114(7):840-845

Stupp R, Mason WP, van den Bent MJ, Weller M, Fisher B, Taphoorn MJ, Belanger K, Brandes AA, Marosi C, Bogdahn U, Curschmann J, Janzer RC, Ludwin SK, Gorlia T, Allgeier A, Lacombe D, Cairncross JG, Eisenhauer E, Mirimanoff RO, R. European Organisation for, T. Treatment of Cancer Brain, G. Radiotherapy, G. National Cancer Institute of Canada Clinical Trials (2005) Radiotherapy plus concomitant and adjuvant temozolomide for glioblastoma. N Engl J Med 352(10):987-996

Weller M, van den Bent M, Tonn JC, Stupp R, Preusser M, CohenJonathan-Moyal E, Henriksson R, Le Rhun E, Balana C, Chinot O, Bendszus M, Reijneveld JC, Dhermain F, French P, Marosi C, Watts C, Oberg I, Pilkington G, Baumert BG, Taphoorn MJB, Hegi M, Westphal M, Reifenberger G, Soffietti R, Wick W (2017)
European Association for Neuro-Oncology (EANO) guideline on the diagnosis and treatment of adult astrocytic and oligodendroglial gliomas. Lancet Oncol 18(6):e315-e329

Weller M, van den Bent M, Preusser M, Le Rhun E, Tonn JC, Minniti G, Bendszus M, Balana C, Chinot O, Dirven L, French P, Hegi ME, Jakola AS, Platten M, Roth P, Ruda R, Short S, Smits M, Taphoorn MJB, von Deimling A, Westphal M, Soffietti R, Reifenberger G, Wick W (2021) EANO guidelines on the diagnosis and treatment of diffuse gliomas of adulthood. Nat Rev Clin Oncol 18(3):170-186

Wen PY, Weller M, Lee EQ, Alexander BM, Barnholtz-Sloan JS, Barthel FP, Batchelor TT, Bindra RS, Chang SM, Chiocca EA, Cloughesy TF, DeGroot JF, Galanis E, Gilbert MR, Hegi ME, Horbinski C, Huang RY, Lassman AB, Le Rhun E, Lim M, Mehta MP, Mellinghoff IK, Minniti G, Nathanson D, Platten M, Preusser M, Roth P, Sanson M, Schiff D, Short SC, Taphoorn MJB, Tonn JC, Tsang J, Verhaak RGW, von Deimling A, Wick W, Zadeh G, Reardon DA, Aldape KD, van den Bent MJ (2020) Glioblastoma in adults: a Society for Neuro-Oncology (SNO) and European Society of Neuro-Oncology (EANO) consensus review on current management and future directions. Neuro Oncol 22(8):1073-1113

Wick W, Platten M, Meisner C, Felsberg J, Tabatabai G, Simon M, Nikkhah G, Papsdorf K, Steinbach JP, Sabel M, Combs SE, Vesper J, Braun C, Meixensberger J, Ketter R, Mayer-Steinacker R, Reifenberger G, Weller M, N. O. A. S. G. o. N.-o. W. G. o. G. C. Society (2012) Temozolomide chemotherapy alone versus radiotherapy alone for malignant astrocytoma in the elderly: the NOA-08 randomised, phase 3 trial. Lancet Oncol 13(7):707-715

Zouaoui S, Darlix A, Fabbro-Peray P, Mathieu-Daude H, Rigau V, Fabbro M, Bessaoud F, Taillandier L, Ducray F, Bauchet F, Wager M, Faillot T, Capelle L, Loiseau H, Kerr C, Menei P, Duffau H, Figarella-Branger D, Chinot O, Tretarre B, Bauchet L (2014) Oncological patterns of care and outcomes for 265 elderly patients with newly diagnosed glioblastoma in France. Neurosurg Rev 37(3):415-423

Publisher's Note Springer Nature remains neutral with regard to jurisdictional claims in published maps and institutional affiliations. 